\title{
The Glomerular Filtration Rate and Proteinuria in Obese Children
}

\author{
Rahime Renda ${ }^{1, *}$ \\ ${ }^{1}$ Pediatric Nephrology Department, Antalya Research and Education Hospital, Antalya, Turkey \\ "Corresponding author: Pediatric Nephrology Department, Antalya Research and Education Hospital, Varlık Mah. Kazık Karabekir, P.O.Box: 07100, Soğuksu/Muratpașa, Antalya, \\ Turkey. Tel: +90-2422494400, Email: rahimeg@yahoo.com \\ Received 2017 December 11; Accepted 2018 January 12.
}

\begin{abstract}
Background: Obesity increases the risk of many pathologies, including cardiovascular and renal diseases. This study aimed to determine the association between obesity and proteinuria as well as glomerular hemodynamic changes (an early marker of kidney damage) in obese children and its relationship with metabolic syndrome.

Methods: This case-control study included 112 overweight and obese male and female patients aged 7 - 16 years, and 35 age- and gender-matched healthy controls. The obese patients were divided into 4 subgroups according to BMI:normal weight (control group), overweight, obese, morbidly obese. The glomerular filtration rate was estimated using classical and adjusted formulas based on the various body size descriptors of Leger, Schwartz, Filler, and Zappitelli, and chronic kidney disease formulas in all patients and controls. Creatinine, cystatin C, 24-hour urine protein, and the estimated glomerular filtration were compared between groups.

Results: Blood pressure, creatinine, and 24-hour urine protein values were significantly higher in the overweight and obese patient subgroups $(\mathrm{P}<0.05)$. The estimated glomerular filtration rate, which was calculated using creatinine or cystatin $\mathrm{C}$, was higher in the obese patients and subgroups than in the control group $(\mathrm{P}<0.05)$. In contrast, the estimated glomerular filtration rate measured using both classical and adjusted formulas was significantly lower in the obese patients than in the controls $(\mathrm{P}<0.05)$.

Conclusions: Early indicators of renal damage are elevated urine protein and renal function test results compatible with impaired renal function. As such, obese pediatric patients should be routinely monitored for blood pressure, renal function, and proteinuria.
\end{abstract}

Keywords: Obesity, Glomerular Filtration Rate, Proteinuria, Metabolic Syndrome

\section{Background}

Overweight and obese children have an increased risk of cardiovascular disease and other obesity-related diseases (1). It is well known that both cardiovascular disease (CVD) and chronic kidney disease (CKD) are epidemiological, medical, and social problems in many developed countries $(2,3)$. Several studies have reported that there is an association between a high BMI, and CKD of multiple causes, nephrolithiasis, and renal cell carcinoma $(4,5)$. It is interesting to note that a review of renal biopsies in obese children with proteinuria showed that they had a 10-fold higher frequency $(0.2 \%-2.0 \%)$ of obesity-related glomerulopathy(ORG), a unique pathology linked to excess weight (6); however, more recent studies provided a more detailed description of ORG and reported that obesity-related structural changes are associated not only with morbid obesity, but also with less severe obesity in a progressive fashion (6). The early marker of ORG is proteinuria (microalbuminuria) together with glomerular hyperfiltration characterized by higher glomerular filtration rate (GFR) than in healthy controls (7). Reports of differences in the eGFR between obese and overweight children are contradictory, some researchers reported higher eGFR in obese children $(8)$, whereas others reported a lower $\operatorname{eGFR}(9,10)$ or no difference $(11,12)$. As the rate of obesity has increased in recent years, the value of $1.73 \mathrm{~m}^{2}$ body surface came under question. There was a theoretical concern in obese patients with a normalizing GFR to body surface area (BSA), but the issue of using absolute values or alternative size descriptors to measure GFR in obese children remains controversial (13).

The majority of earlier studies on the relationship between obesity and renal function have been conducted with adult obese patients; relevant data regarding obese children and adolescents are limited (14).

\section{Objectives}

The aim of the present study was to determine the effect of proteinuria and the effect of indexing to various body size descriptors on eGFR in overweight, obese, 
and normal weight children, and to show its relation with metabolic syndrome (MS).

\section{Methods}

This study included male and female children aged 7 - 16 years that presented to our pediatric endocrinology outpatient clinic with a BMI > 95th percentile for age and gender, and a diagnosis of overweight or obesity. The control group included age- and gender-matched children with a normal BMI for age and gender, and a negative history of kidney and systemic disease. The patients were divided into 4 subgroups according to BMI and zscore:normal weight (control group), overweight, obese, and morbidly obese. Patients that were using glucose- or lipid-lowering drugs and/or anti-hypertensive medication, and those with renal disease, diabetes mellitus (DM), genetic syndromes, and hypo- or hyperthyroidism were excluded from the study. Demographic and clinical data (medical history, and clinical examination, laboratory, and radiological findings) were recorded for all the participants. Fasting blood samples were drawn for assessment of glucose, insulin, glycated hemoglobin A1c $\left(\mathrm{HbA}_{1 \mathrm{c}}\right)$, lipid, urea, creatinine, and cystatin $\mathrm{C}$ (Cys-C) levels, thyroid function, and the alanine aminotransferase (ALT) level. Each participant was instructed to avoid exercise for 24 hours prior to sampling. Females were instructed not to collect urine specimens during menstruation. The study protocol was approved by our hospital ethics committee (5/216.03.2017) and carried out in accordance with the declaration of Helsinki. Written informed consent was received by the participants or their parents.

Pubertal stage was determined according to Tanner, and height, weight, and waist circumference (WC) were estimated. BMI $\left(\mathrm{kg} / \mathrm{m}^{2}\right)$ was measured by dividing body weight $(\mathrm{kg})$ by squared height $\left(\mathrm{m}^{2}\right)$. BMI for age values were classified as normal weight $(\leq+1 \mathrm{SD})$, overweight $(>+$ $1 \mathrm{SD}$ and $\leq+2 \mathrm{SD}$ ), obese ( $>2 \mathrm{SD}$ and $\leq+3 \mathrm{SD})$, and morbidly obese $(>+3 \mathrm{SD})$ (15). Lean body mass (LBM) was measured via the Peters formula (16), BSA was measured via the Haycock equation (17), and ideal body weight (IBW) multiplied squared height by BMI at 50th percentiles (18). Patients were classified as having MS based on $\geq 3$ of the following parameters: abdominal obesity (elevated WC and an elevated waist-height ratio), hypertension, hyperglycemiainsulin resistance, a high triglyceride (TG) level, and a low HDL level (19).

Blood pressure (BP) was measured separately 3 times consecutively at 5-minute intervals with participants in the seated position, using a mercury sphygmomanometer and a cuff matched to arm circumference. Systolic blood pressure (SBP) and diastolic blood pressure (DBP) were based on the mean of 3 measurements. BP had to be persistently $\geq 95$ th percentile of the BP distribution in a normal reference population on $\geq 3$ separate occasions to be considered indicative of hypertension. High-normal BP was considered as SBP and/or DBP $\geq 90$ th percentile or $<$ 95th percentile. Adolescents with a $\mathrm{BP} \geq 120 / 80 \mathrm{mmHg}$ were considered high-normal BP even if the measurement was $<90$ th percentile. Participants in which both SBP and DBP were $<$ 90th percentile for age, gender, and height were considered normotensive (20).

Glucose, urea, creatinine, cholesterol, triglyceride, HDL, and urine protein were measured using a Beckman Coulter AU5800 (Beckman Coulter Inc., USA), and the conventional spectrophotometric method and Beckman Coulter commercial kits. The 24-hour urine protein level was also calculated. In addition, insulin, TSH, and FT4 were measured using a Beckman Coulter Dxl 800 (Beckman Coulter Inc., USA) and the chemiluminescence method. The $\mathrm{HbA}_{1 \mathrm{c}}$ level was determined using commercially available kits and high-performance liquid chromatography (Tosoh HLC 723 G8; Tosoh Bioscience, Japan). Serum Cys$\mathrm{C}$ was measured using a particle-enhanced immunonephelometric assay (N Latex CysC; Siemens, Erlangen, Germany) before administration of the certified reference material (ERM-DA471/IFCC).

For the 24-hour urine protein test, urine specimens were collected into plastic or glass containers over a 24 hour period. At the start time urine specimens were not collected, but at the end of 24-hour urine sample was drained into container. The containers were stored cool before being sent for laboratory analysis. The 24-hour urine specimens were accepted as valid if urinary volume was $>300 \mathrm{~mL}$ and if urinary creatinine was $11.3-28.0 \mathrm{mg} / \mathrm{kg} / \mathrm{d}$ (21). All the participants' parents received written and oral instructions for the correct method of collection. The normal 24-hour urine protein value was considered $<80$ $\mathrm{mg} / \mathrm{d}$.

eGFR $\left(\mathrm{mL} / \mathrm{min} / 1.73 \mathrm{~m}^{2}\right)$ was measured using creatininebased formulas (Schwartz, Leger) (22, 23), Cys-C-based formulas (Filler, Zappitelli) $(24,25)$, and Cys-C plus creatininebased formulas (CKID, Zappitelli) $(25,26)$. The absolute GFR was measured by multiplying BSA by the eGFR values, and then dividing by $1.73 \mathrm{~m}^{2}$. In clinical practice to receive generally used value (standard in $1.73 \mathrm{~m}^{2}$ body surface), the absolute GFR value was multiplied by 1.73 and divided by the patients BSA, measured by the Haycock formula (17). To approve alternative GFR adapters by the ratio method, absolute GFR rates were divided by the value of body size descriptor, and received different GFR rates adapted to several body size descriptors (13). Hyperfiltration was determined as a GFR > $134.3 \mathrm{~mL} / \mathrm{min}$, in accordance with published reference ranges (27). 


\subsection{Statistical Analysis}

All the data was entered, checked for missing values, and analyzed using SAS v.9.4 (SAS Institute, Cary, NC, USA). Descriptive statistics, including mean $\pm \mathrm{SD}$, were used to describe the primary variables. The Kolmogorov-Smirnov test was used to assess the normality of the distribution of the variables in order to appropriately use parametric or non-parametric tests. All variables were normally distributed; therefore, such parametric tests as analysis of variance and the $t$ test were used to determine the differences in variables between groups. A two-sided P value $<$ 0.05 was considered statistically significant.

\section{Results}

The study included 147 children (patient group: $\mathrm{n}=112$; control group: $\mathrm{n}=35)$. Among those in the patient group, 10 (8.9\%) were in the overweight subgroup, 84 (75\%) were in the obese subgroup, and 18 (16.1\%) were in the morbidly obese subgroup. In addition, 51 of the patients (all were obese) had hypertension. Hypertension was not observed in the control group. As the z-score increased in the patient group, SBP and DBP both increased. The hypertension frequency rate was significantly higher in the overweight, obese and morbidly obese patients than in the control group, and was significantly higher in the 12 (66\%) patients in the morbidly obese group than in the other patients $(\mathrm{P}<0.05)$. Moreover, $19(17 \%)$ of the patients in the obese subgroup fulfilled the criteria for MS. There weren't any significant differences in laboratory parameters (fasting glycemia and insulin, cholesterol, triglyceride, $\mathrm{HbA}_{1}$, and thyroid function test results) between the patient and control groups $(\mathrm{P}>0.05)$. Demographic data and patient body size descriptors are summarized in Table 1 .

Creatinine, Cys-C, and 24-hour protein levels were compared between all obese patients, between obese patients with and without MS, and between the patient and control groups. Creatinine and 24-hour protein levels were significantly higher in the patient group than in the control group $(\mathrm{P}<0.05)$, whereas the Cys-C level was similar in both groups. The highest 24-hour urine protein level was noted in the obese patients with MS, and the creatinine and urine protein levels were significantly higher in the obese patients and subgroups than in the control group ( $\mathrm{P}$ $<0.05$ ) (Figure 1).

GFR was measured using creatinine-based formulas (Schwartz, Leger), Cys-C-based formulas (Filler, Zappitelli), and Cys-C plus creatinine-based formulas (CKID, Zappitelli). Classical and adjusted estimates of GFR were compared between all the obese patients, between the obese patients with and without MS, and control group. Based on the classical Schwartz, Filler, and Zappitelli formulas without any adjustment and the corrected IBW-adjusted formula by Leger, the eGFR was higher in the obese patients with MS, but not significantly ( $>>0.05)$. Among the GFR estimating formulas based on creatinine, Leger adjusted to LBM and BSA-IBW, the eGFR was significantly higher in the obese patients with and without MS than in conrols $(\mathrm{P}<0.05)$. In contrast, using the Leger BSA-adjusted formula, the eGFR was significantly lower in all obese patients with and without MS than in controls $(\mathrm{P}<0.05)$. Based on all forms (adjusted and non-adjusted) of combined formulas (using creatinine and Cys-C), the eGFR was significantly lower in the overweight and obese patient subgroups $(\mathrm{P}<$ 0.05). Conversely, the eGFR based only on the classical CKID formula was higher in the obese patients with MS than in obese patients without MS and controls (Table 2).

\section{Discussion}

Obesity is known to lead to the development of several metabolic abnormalities, including hypertension, and impaired glucose, lipid, and insulin metabolism. Pediatric studies have shown that obesity and its complications start early in life and lead to cardiovascular events, diabetes, and renal disease (28). Early findings of renal damage include proteinuria (microalbuminuria), high blood pressure, and impaired renal function (29). Earlier relevant studies have primarily included adolescents, but in recent years the study of obesity in children and its association with MS has become more common $(30,31)$.

Hypertension is common in children with excess weight. Obesity directly elevates blood pressure via increases in stroke volume, blood volume, and cardiac output, with peripheral vascular resistance (29). As a reason obesity activates renin-angiotensin-aldosterone system (RAAS) with relative efferent arteriolar vasoconstriction due to increased production of angiotensin II and aldosterone. Moreover, enhanced sympathetic activity leads to efferent arteriolar constriction and an increase in renal plasma flow with volume expansion, causing hypertension (32). Adults with a BMI $>35 \mathrm{~kg} / \mathrm{m}^{2}$ have a 6 -fold higher risk of hypertension than adults with a BMI of 18.5 $-24.9 \mathrm{~kg} / \mathrm{m}^{2}$. It was reported that there is a relationship between high weight and hypertension in overweight and obese students (33). In the present study as BMI increased, blood pressure increased proportionally. Similar to earlier reports $(34,35)$, in our study both SBP and DBP were significantly higher especially in obese patients with MS.

An important aim of the present study was to determine the relationship between an elevated urine protein level and MS; therefore, 24-hour urine was collected from 


\begin{tabular}{|c|c|c|c|c|c|}
\hline & Overweight $(n=10)$ & Obese $(n=84)$ & Morbidly Obese $(n=18)$ & Control $(\mathbf{n}=\mathbf{3 5})$ & $\mathbf{P}$ \\
\hline Male/female, $n$ & $5 / 5$ & $36 / 48$ & $8 / 10$ & $21 / 14$ & 0.387 \\
\hline Age $(y)$ & $10.79 \pm 1.20$ & $10.15 \pm 1.55$ & $10.98 \pm 1.62$ & $9.84 \pm 2.88$ & 0.499 \\
\hline Puberty (pre/pub-post) & $3 / 7$ & $19 / 65$ & $4 / 14$ & $23 / 12$ & 0.866 \\
\hline Height SDS & $145.14 \pm 10.57$ & $147.08 \pm 10.33$ & $140.48 \pm 5.76$ & $136.76 \pm 16.08$ & 0.036 \\
\hline Weight (kg) & $49.83 \pm 9.62$ & $62.37 \pm 14.53$ & $69.96 \pm 11.43$ & $32.2 \pm 9.65$ & 0.000 \\
\hline BMI $\left(\mathrm{kg} \mathrm{m}^{-2}\right)$ & $23.31 \pm 1.77$ & $28.95 \pm 3.43$ & $35.26 \pm 3.99$ & $17.06 \pm 2.18$ & 0.000 \\
\hline BMI z-score & $1.51 \pm 0.28$ & $2.56 \pm 0.36$ & $3.62 \pm 0.13$ & $-0.22 \pm 0.99$ & 0.000 \\
\hline LBM (kg) & $37.59 \pm 6.63$ & $43.84 \pm 8.63$ & $45.64 \pm 5.89$ & $28.22 \pm 8.3$ & 0.000 \\
\hline $\operatorname{BSA}\left(\mathbf{m}^{2}\right)$ & $1.43 \pm 0.19$ & $1.61 \pm 0.24$ & $1.69 \pm 0.17$ & $1.13 \pm 0.25$ & 0.000 \\
\hline IBW $(\mathbf{k g})$ & $25.04 \pm 2.21$ & $25.78 \pm 3.47$ & $24.04 \pm 2.44$ & $24.39 \pm 5.74$ & 0.546 \\
\hline $\operatorname{BSA} \operatorname{IBW}\left(\mathbf{m}^{2}\right)$ & $0.99 \pm 0.06$ & $1.01 \pm 0.1$ & $0.95 \pm 0.06$ & $0.95 \pm 0.16$ & 0.294 \\
\hline SBP $(\mathbf{m m H g})$ & $109.33 \pm 9.83$ & $117.09 \pm 8.13$ & $118.5 \pm 4.2$ & $89 \pm 9.84$ & 0.000 \\
\hline $\mathrm{DBP}(\mathrm{mmHg})$ & $66.83 \pm 3.82$ & $74.3 \pm 10.61$ & $74.75 \pm 5.74$ & $55.71 \pm 5.17$ & 0.000 \\
\hline Hypertension, $\mathbf{n}(\%)$ & $2(20)$ & $37(44)$ & $12(66)$ & $0(0)$ & 0.000 \\
\hline Fasting glycemia $\left(\mathrm{mg} \mathrm{dL}^{-1}\right)$ & $87 \pm 6.3$ & $87.82 \pm 9.04$ & $83.6 \pm 5.5$ & - & 0.580 \\
\hline $\mathbf{H b A}_{1 \mathbf{c}}(\%)$ & $5.85 \pm 0.78$ & $5.63 \pm 0.93$ & $5.4 \pm 0.36$ & - & 0.940 \\
\hline Fasting insulin ( $\left.\mathrm{uIU} \mathrm{mL} \mathbf{~}^{-1}\right)$ & $12.91 \pm 9.3$ & $15.55 \pm 9.3$ & $21.57 \pm 12.87$ & - & 0.461 \\
\hline Total cholesterol $\left(\mathrm{mg} \mathrm{dL}^{-1}\right)$ & $157.1 \pm 21.52$ & $160.59 \pm 32.16$ & $190.25 \pm 61.77$ & - & 0.242 \\
\hline HDL-cholesterol $\left(\mathrm{mg} \mathrm{dL}^{-1}\right)$ & $47.2 \pm 7.83$ & $44.08 \pm 8.77$ & $51.2 \pm 13.54$ & - & 0.231 \\
\hline Triglycerides $\left(\mathrm{mg} \mathrm{dL}^{-1}\right)$ & $156.4 \pm 90.11$ & $138.54 \pm 60.85$ & $125.4 \pm 70.96$ & - & 0.845 \\
\hline $\operatorname{TSH}\left(\mathbf{u I U ~ m L} \mathbf{~}^{-1}\right)$ & $1.8 \pm 1.14$ & $3.02 \pm 1.54$ & $3.28 \pm 1.02$ & - & 0.155 \\
\hline FT4 $\left(n g\right.$ dL $\left.^{-1}\right)$ & $0.88 \pm 0.1$ & $0.94 \pm 0.43$ & $0.83 \pm 0.1$ & - & 0.809 \\
\hline Metabolic syndrome, $\mathbf{n}(\%)$ & $1(10)$ & $16(19)$ & $2(11)$ & $0(0)$ & 0.644 \\
\hline
\end{tabular}

Abbreviations: BMI, body mass index; BMI z-score, standard deviation score of body mass index; BSA IBW, body surface area calculated using each participant's ideal body weight; BSA, body surface area; DBP, diastolic blood pressure; FT4, free thyroxine; HbA1c, glycosylated hemoglobin; HDL, high-density lipoprotein; IBW, ideal body weight; LBM, lean body mass; SBP, systolic blood pressure; SDS, Standard deviation score; TSH, thyroid-stimulating hormone.

${ }^{a}$ Statistical significance: $\mathrm{P}<0.05$.

the patients and controls, protein excretion was calculated, and then the results were compared between all the patients, between the obese patients with and without MS, and between the patients and control group. A higher prevalence of proteinuria was previously reported in obese children, which was associated with BMI (36) and impaired glucose metabolism (37). In the present study urinary protein excretion was higher in the patients, especially obethisse patients with MS, as compared to the controls. Although the majority of the present study's obese patients had urinary protein excretion $<150 \mathrm{mg} / 24$-hour; because it was significantly higher than in the controls, we think these patients should be monitored closely for early renal damage. ORG is characterized by a lower prevalence of nephrotic syndrome, slower progression of proteinuria, kidney failure, and glomerulomegaly, and less segmental sclerosis, as compared to idiopathic focal seg- mental glomerulosclerosis (28).

It is well known that during the early stage of kidney dysfunction associated with obesity hyperfiltration develops as an adaptation of the kidneys to increased body mass (7). Creatinine and Cys-C, as impaired renal function indicators, have high values in many studies $(26,38)$. In the present study the creatinine level was higher in the obese patient subgroup, differently with the cystatin $C$ values being slightly higher, were found similar in all groups, which was most likely because the patients were shorter than expected.

Several formulas based both on Cys-C and creatinine have been recommended for calculation of the GFR in children and adults (39). Some researchers reported high GFR values in obese patients $(34,36)$, whereas others reported low GFR values $(26,38)$. Because of difficulty in collecting 24-hour urine in children, 24-hour creatinine clearance re- 
A

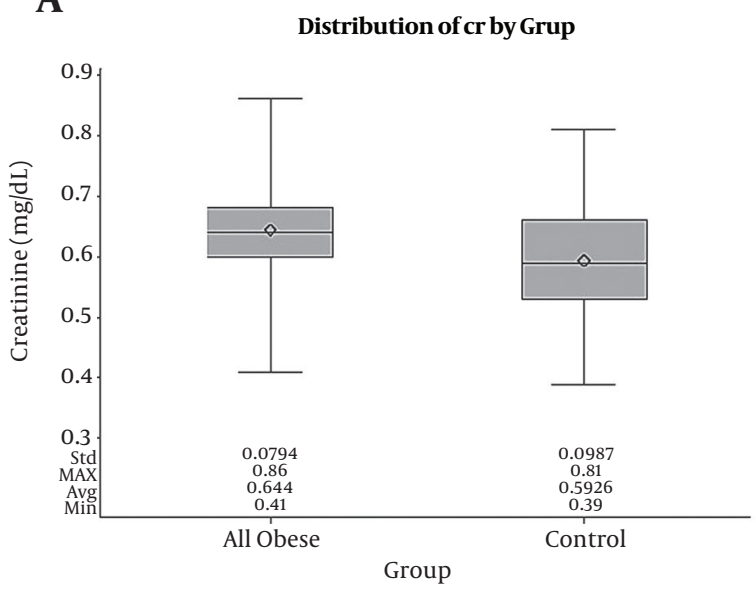

C

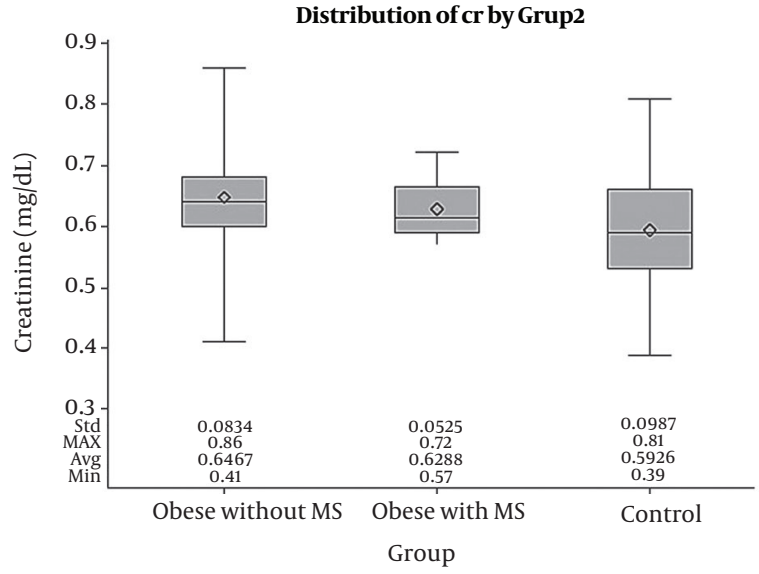

B

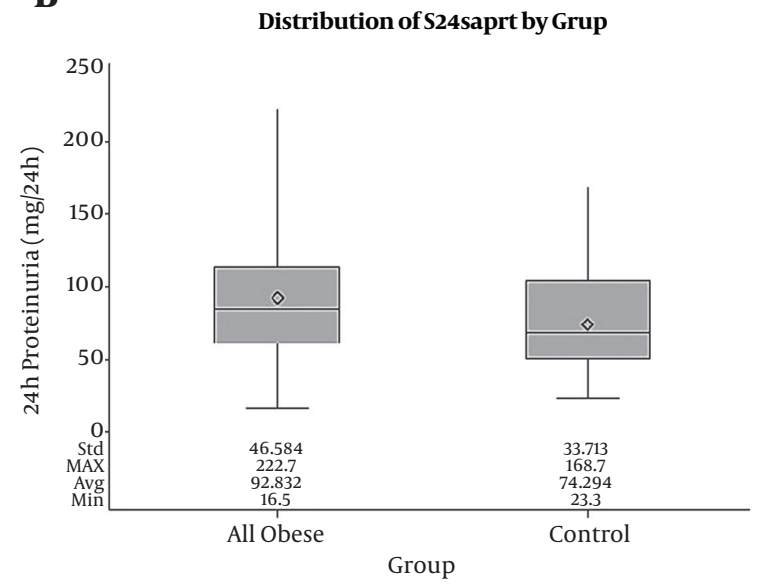

D

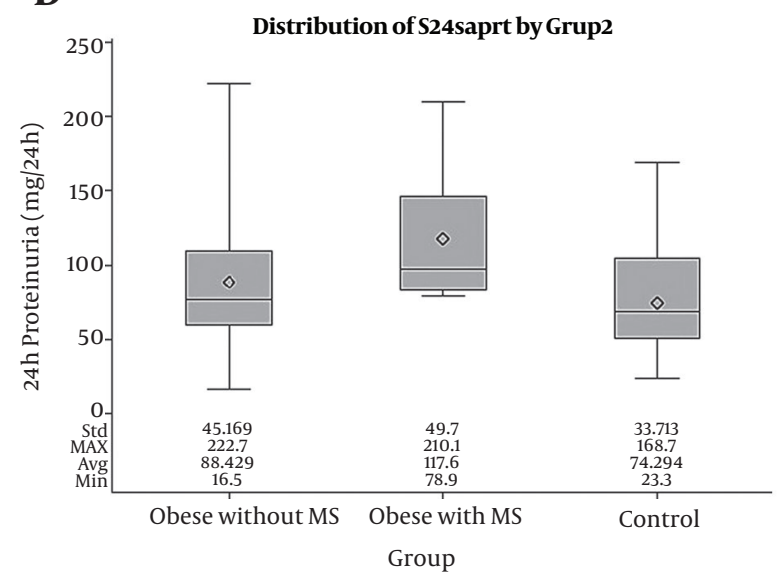

Figure 1. Creatinine and 24-hour protein values according to subgroups. A, creatinine values in all the obese patients and controls; B, 24-hour protein values in all the obese patients and controls; C, creatinine values in the obese patients with MS, obese patients without MS, and the control group; D, 24-hour protein values in the obese patients with MS, obese patients without MS, and the control group (the line inside the rectangle shows the median and the box limits correspond to the interquartile range (the first and the third quartile)). Whiskers above and below the box indicate the location of the minimum and maximum.

sults were rarely reported (28). A recent study in adults showed the possible differential performance of GFR equations in subgroups determined based on body composition (40); the absolute difference between subgroups was smallest when a combination of formulas was used and the researchers recommended using a combination of formulas, especially in subgroups in which body might intervene (40). Inconsistencies in GFR calculation adjusted for body size in overweight and obese children are due to the fact that a body size descriptor vulnerable on weight, normalization to conventional BSA, results in lower GFR values in these children than in normal weight children. Hyperfiltration in overweight and obese children was reported to be a marker of early-stage obesity-associated kidney dysfunction (28). In the present study the effect of GFR normalization with various anthropometric descriptors of body size in overweight, obese, and normal weight children was assessed. As previously reported, in the present study GFR values were higher when non-normalization formulas based on creatinine only or Cys-C only were used, whereas GFR values in obese patients and subgroups based on classical and adjusted combined formulas were lower than in the control group. These findings are consistent with earlier studies $(26,28)$ that recommended use of an adjusted combined formula for calculating the GFR.

\subsection{Conclusions}

The incidence of childhood obesity and obesityassociated diseases continues to increase rapidly. It is extremely important that obesity-related organ damage 


\begin{tabular}{|c|c|c|c|c|c|}
\hline GFR Estimating Formulas & All Obese Patients $(n=112)$ & $\begin{array}{l}\text { Obese Patients with MS (n } \\
=19)\end{array}$ & $\begin{array}{l}\text { Obese Patients Without MS } \\
\qquad(\mathbf{n}=93)\end{array}$ & Controls $(\mathbf{n}=35)$ & $\mathbf{P}$ \\
\hline \multicolumn{6}{|l|}{ GFR based on creatinine } \\
\hline Leger & $115.4 \pm 19.98$ & $132.56 \pm 25.87$ & $112.35 \pm 17.38$ & $89.33 \pm 20.94$ & $0.000,0.000$ \\
\hline $\begin{array}{l}\text { LBM-adjusted GFR via } \\
\text { Leger }\end{array}$ & $97.17 \pm 14.66$ & $110.14 \pm 18.57$ & $94.86 \pm 12.77$ & $83.55 \pm 18.92$ & $0.000,0.000$ \\
\hline $\begin{array}{l}\text { IBW-adjusted GFR via } \\
\text { Leger }\end{array}$ & $79.59 \pm 10.55$ & $88.45 \pm 12.16$ & $78.01 \pm 9.55$ & $79.55 \pm 17$ & $0.989,0.126$ \\
\hline $\begin{array}{l}\text { BSA-adjusted GFR via } \\
\text { Leger }\end{array}$ & $72.55 \pm 8.28$ & $75.36 \pm 6.31$ & $72.06 \pm 8.55$ & $80.06 \pm 13$ & $0.001,0.004$ \\
\hline $\begin{array}{l}\text { BSA-IBW-adjusted } \\
\text { GFR via Leger }\end{array}$ & $115.37 \pm 15.17$ & $124.09 \pm 14.95$ & $113.82 \pm 14.83$ & $93.89 \pm 14.12$ & $0.000,0.000$ \\
\hline Schwartz & $94.8 \pm 10.42$ & $100.85 \pm 9.56$ & $93.73 \pm 10.29$ & $98.13 \pm 15.22$ & $0.226,0.161$ \\
\hline \multicolumn{6}{|l|}{ GFR based on Cys-C } \\
\hline Filler & $142.67 \pm 25.8$ & $158.83 \pm 31.54$ & $139.8 \pm 23.92$ & $145.94 \pm 20.5$ & $0.530,0.091$ \\
\hline Zappitelli & $120.55 \pm 22.71$ & $134.82 \pm 27.84$ & $118.01 \pm 21.04$ & $123.39 \pm 18.05$ & $0.534,0.090$ \\
\hline \multicolumn{6}{|l|}{$\begin{array}{l}\text { GFR based on creatinine } \\
\text { and Cys-C }\end{array}$} \\
\hline CKID & $101.72 \pm 9.97$ & $110.69 \pm 9.93$ & $100.13 \pm 9.19$ & $104.02 \pm 12.39$ & $0.399,0.025$ \\
\hline Zappitelli & $74.80 \pm 9.93$ & $80.23 \pm 10.11$ & $73.83 \pm 9.69$ & $79.78 \pm 11.45$ & $0.032,0.029$ \\
\hline $\begin{array}{l}\text { BMI-adjusted GFR via } \\
\text { CKID }\end{array}$ & $3.6 \pm 0.58$ & $3.74 \pm 0.55$ & $3.58 \pm 0.59$ & $6.21 \pm 1.21$ & $0.000,0.000$ \\
\hline $\begin{array}{l}\text { BMI-adjusted GFR via } \\
\text { Zappitelli }\end{array}$ & $2.65 \pm 0.54$ & $2.71 \pm 0.48$ & $2.64 \pm 0.55$ & $4.78 \pm 1.1$ & $0.000,0.000$ \\
\hline $\begin{array}{l}\text { BSA-adjusted GFR via } \\
\text { CKID }\end{array}$ & $65.07 \pm 10.91$ & $64.24 \pm 11.19$ & $65.21 \pm 10.99$ & $96.22 \pm 22.63$ & $0.000,0.000$ \\
\hline $\begin{array}{l}\text { BSA-adjusted GFR via } \\
\text { Zappitelli }\end{array}$ & $48.21 \pm 11.16$ & $46.6 \pm 9.31$ & $48.50 \pm 11.53$ & $75.03 \pm 22.86$ & $0.000,0.000$ \\
\hline $\begin{array}{l}\text { LBM-adjusted GFR via } \\
\text { CKID }\end{array}$ & $2.44 \pm 0.51$ & $2.33 \pm 0.49$ & $2.46 \pm 0.52$ & $3.97 \pm 1.17$ & $0.000,0.000$ \\
\hline $\begin{array}{l}\text { LBM-adjusted GFR via } \\
\text { Zappitelli }\end{array}$ & $1.81 \pm 0.5$ & $1.69 \pm 0.39$ & $1.83 \pm 0.52$ & $3.11 \pm 1.13$ & $0.000,0.000$ \\
\hline $\begin{array}{l}\text { IBW-adjusted GFR via } \\
\text { CKID }\end{array}$ & $4.04 \pm 0.61$ & $4.04 \pm 0.59$ & $4.05 \pm 0.62$ & $4.46 \pm 1.01$ & $0.019,0.065$ \\
\hline $\begin{array}{l}\text { IBW-adjusted GFR via } \\
\text { Zappitelli }\end{array}$ & $2.99 \pm 0.62$ & $2.93 \pm 0.52$ & $3.00 \pm 0.64$ & $3.49 \pm 1.06$ & $0.006,0.026$ \\
\hline $\begin{array}{l}\text { BSA-IBW-adjusted } \\
\text { GFR via CKID }\end{array}$ & $102.66 \pm 13.24$ & $104.86 \pm 13.49$ & $102.26 \pm 13.31$ & $111.88 \pm 20.51$ & $0.012,0.039$ \\
\hline $\begin{array}{l}\text { BSA-IBW-adjusted } \\
\text { GFR via Zappitelli }\end{array}$ & $75.8 \pm 13.87$ & $76.06 \pm 12.28$ & $75.75 \pm 14.26$ & $87.07 \pm 22.67$ & $0.004,0.019$ \\
\hline
\end{tabular}

Abbreviations: CKID, chronic kidney disease in children; GFR, glomerular filtration rate.

a Adjusted GFR values for each size descriptor were measured by dividing the absolute GFR by the frequency of the size descriptor in each participant.

${ }^{\mathrm{b}}$ Statistical significance $\mathrm{P}<0.05$.

in pediatric patients is correctly treated as early as possible to ensure optimal outcomes. Additional research is necessary to identify the optimal normalization of GFR to multiple body size descriptors.

What is already known on this topic?

It's very important to evaluate urinary protein and glomerular filtration rate in detecting and following re- nal damage in obese children. There are some problems in obese patients without evaluating glomerular filtration rate. For this reason this issue is still controversial.

What this study adds?

Obese patients have wider body surface areas, calculating GFR by conventional methods may lead to errors in these patients. So it is very important to calculate GFR with 
corrected formulas using different body measurements in these patients. We hope that we will be attracting interest in our work because there are not enough publications about obese children.

\section{Acknowledgments}

The study protocol was conducted in accordance with the declaration of Helsinki and approved by the Antalya research and education hospital ethics committee. Written informed consent was provided by the patient family before the start of study.

\section{References}

1. Srivastava T. Nondiabetic consequences of obesity on kidney. Pediatr Nephrol. 2006;21(4):463-70. doi: 10.1007/s00467-006-0027-4. [PubMed: 16491417].

2. Flegal KM. Prevalence and Trends in Obesity Among US Adults, 1999 2000. Am Med Assoc. 2002;288(14):1723. doi: 10.1001/jama.288.14.1723.

3. Zoccali C, Seck SM, Mallamaci F. Obesity and the epidemiology and prevention of kidney disease: waist circumference versus body mass index. Am J Kidney Dis. 2011;58(2):157-9. doi: 10.1053/j.ajkd.2011.05.009. [PubMed: 21787980].

4. Wang Y, Chen X, Song Y, Caballero B, Cheskin LJ. Association between obesity and kidney disease: a systematic review and meta-analysis. Kidney Int. 2008;73(1):19-33. doi: 10.1038/sj.ki.5002586. [PubMed: 17928825].

5. Gorbachinsky I, Akpinar H. Metabolic syndrome and urologic diseases. Rev Urol. 2009;75:585-95.

6. Kambham N, Markowitz GS, Valeri AM, Lin J, D’Agati VD. Obesityrelated glomerulopathy: an emerging epidemic. Kidney Int. 2001;59(4):1498-509. doi: 10.1046/j.1523-1755.2001.0590041498.x. [PubMed: 11260414].

7. Tomaszewski M, Charchar FJ, Maric C, McClure J, Crawford L, Grzeszczak W, et al. Glomerular hyperfiltration: a new marker of metabolic risk. Kidney Int. 2007;71(8):816-21. doi:10.1038/sj.ki.5002160. [PubMed: 17332732].

8. Koulouridis E, Georgalidis K, Kostimpa I, Koulouridis I, Krokida A, Houliara D. Metabolic syndrome risk factors and estimated glomerular filtration rate among children and adolescents. Pediatr Nephrol. 2010;25(3):491-8. doi: 10.1007/s00467-009-1364-x. [PubMed: 20012104].

9. Duzova A, Yalcinkaya F, Baskin E, Bakkaloglu A, Soylemezoglu O. Prevalence of hypertension and decreased glomerular filtration rate in obese children: results of a population-based field study. Nephrol Dial Transplant. 2013;28 Suppl 4:iv166-71. doi: 10.1093/ndt/gft317. [PubMed: 24179010].

10. Soylemezoglu O, Duzova A, Yalcinkaya F, Arinsoy T, Suleymanlar G. Chronic renal disease in children aged 5-18 years: a population-based survey in Turkey, the CREDIT-C study. Nephrol Dial Transplant. 2012;27 Suppl 3:iii146-51. doi: 10.1093/ndt/gfs366. [PubMed: 23115139].

11. Goknar N, Oktem F, Ozgen IT, Torun E, Kucukkoc M, Demir AD, et al. Determination of early urinary renal injury markers in obese children. Pediatr Nephrol. 2015;30(1):139-44. doi:10.1007/s00467-014-28290. [PubMed: 24801174].

12. Cindik N, Baskin E, Agras PI, Kinik ST, Turan M, Saatci U. Effect of obesity on inflammatory markers and renal functions. Acta Paediatr. 2005;94(12):1732-7. doi: 10.1080/08035250500277101. [PubMed: $16421032]$.

13. Correia-Costa L, Schaefer F, Afonso AC, Bustorff M, Guimaraes JT, Guerra A, et al. Normalization of glomerular filtration rate in obese children. Pediatr Nephrol. 2016;31(8):1321-8. doi: 10.1007/s00467-0163367-8. [PubMed: 27008644].

14. Savino A, Pelliccia P, Chiarelli F, Mohn A. Obesity-related renal injury in childhood. Horm Res Paediatr. 2010;73(5):303-11. doi: 10.1159/000308161. [PubMed: 20389099].

15. de Onis M, Onyango AW, Borghi E, Siyam A, Nishida C, Siekmann J. Development of a WHO growth reference for school-aged children and adolescents. Bull World Health Organ. 2007;85(9):660-7. [PubMed: 18026621]. [PubMed Central: PMC2636412].

16. Peters AM, Snelling HL, Glass DM, Bird NJ. Estimation of lean body mass in children. Br J Anaesth. 2011;106(5):719-23. doi: 10.1093/bja/aer057. [PubMed: 21498495].

17. Haycock GB, Schwartz GJ, Wisotsky DH. Geometric method for measuring body surface area: a height-weight formula validated in infants, children, and adults. J Pediatr. 1978;93(1):62-6. [PubMed: 650346].

18. Ross EL, Jorgensen J, DeWitt PE, Okada C, Porter R, Haemer M, et al. Comparison of 3 body size descriptors in critically ill obese children and adolescents: implications for medication dosing. J Pediatr Pharmacol Ther. 2014;19(2):103-10. doi: 10.5863/1551-6776-19.2.103. [PubMed: 25024670]. [PubMed Central: PMC4093662].

19. Zimmet P, Alberti KG, Kaufman F, Tajima N, Silink M, Arslanian S, et al. The metabolic syndrome in children and adolescents - an IDF consensus report. Pediatr Diabetes. 2007;8(5):299-306. doi: 10.1111/j.13995448.2007.00271.x. [PubMed: 17850473].

20. Lurbe E, Cifkova R, Cruickshank JK, Dillon MJ, Ferreira I, Invitti C, et al. Management of high blood pressure in children and adolescents: recommendations of the European Society of Hypertension. J Hypertens. 2009;27(9):1719-42. doi: 10.1097/HJH.0b013e32832f4f6b. [PubMed: 19625970].

21. Remer T, Neubert A, Maser-Gluth C. Anthropometry-based reference values for 24-h urinary creatinine excretion during growth and their use in endocrine and nutritional research. Am J Clin Nutr. 2002;75(3):561-9. doi:10.1093/ajcn/75.3.561. [PubMed: 11864864].

22. Schwartz GJ, Munoz A, Schneider MF, Mak RH, Kaskel F, Warady BA, et al. New equations to estimate GFR in children with CKD. J Am Soc Nephrol. 2009;20(3):629-37. doi: 10.1681/ASN.2008030287. [PubMed: 19158356]. [PubMed Central: PMC2653687].

23. Leger F, Bouissou F, Coulais Y, Tafani M, Chatelut E. Estimation of glomerular filtration rate in children. Pediatr Nephrol. 2002;17(11):903-7. doi: 10.1007/s00467-002-0964-5. [PubMed: 12432431].

24. Filler G, Lepage N. Should the Schwartz formula for estimation of GFR be replaced by cystatin C formula? Pediatr Nephrol. 2003;18(10):981-5. doi: 10.1007/s00467-003-1271-5. [PubMed: 12920638].

25. Zappitelli M, Parvex P, Joseph L, Paradis G, Grey V, Lau S, et al. Derivation and validation of cystatin C-based prediction equations for GFR in children. Am J Kidney Dis. 2006;48(2):221-30. doi: 10.1053/j.ajkd.2006.04.085. [PubMed:16860187].

26. Schwartz GJ, Schneider MF, Maier PS, Moxey-Mims M, Dharnidharka VR, Warady BA, et al. Improved equations estimating GFR in children with chronic kidney disease using an immunonephelometric determination of cystatin C. Kidney Int. 2012;82(4):44553. doi: 10.1038/ki.2012.169. [PubMed: 22622496]. [PubMed Central: PMC3433576].

27. Fadrowski JJ, Neu AM, Schwartz GJ, Furth SL. Pediatric GFR estimating equations applied to adolescents in the general population. Clin J Am Soc Nephrol. 2011;6(6):1427-35. doi: 10.2215/CJN.06460710. [PubMed: 21566103]. [PubMed Central: PMC3109941].

28. Correia-Costa L, Azevedo A, Afonso AC. Obesity-related nephropathy in children-the need for greater awareness. Port J Nephr Hypertension. 2016;30(2):89-93.

29. Alicic RZ, Patakoti R, Tuttle KR. Direct and indirect effects of obesity on the kidney. Adv Chronic Kidney Dis. 2013;20(2):121-7. doi: 10.1053/j.ackd.2012.12.006. [PubMed: 23439370]. 
30. Franks PW, Hanson RL, Knowler WC, Sievers ML, Bennett PH, Looker HC. Childhood obesity, other cardiovascular risk factors, and premature death. N Engl J Med. 2010;362(6):485-93. doi: 10.1056/NEJMoa0904130. [PubMed: 20147714]. [PubMed Central: PMC2958822].

31. Viggiano D, De Filippo G, Rendina D, Fasolino A, D'Alessio N, Avellino $\mathrm{N}$, et al. Screening of metabolic syndrome in obese children: a primary care concern.JPediatr Gastroenterol Nutr.2009;49(3):329-34. doi: 10.1097/MPG.0b013e31819b54b7. [PubMed: 19590449].

32. Sowers JR, Whaley-Connell A, Epstein M. Narrative review: the emerging clinical implications of the role of aldosterone in the metabolic syndrome and resistant hypertension. Ann Intern Med. 2009;150(11):776-83. [PubMed: 19487712]. [PubMed Central: PMC2824330].

33. Rutkowski B, Czarniak P, Krol E, Szczesniak P, Zdrojewski T. Overweight, obesity, hypertension and albuminuria in Polish adolescents-results of the Sopkard 15 study. Nephrol Dial Transplant. 2013;28 Suppl 4:iv204-11. doi: 10.1093/ndt/gft328. [PubMed: 24068778].

34. Franchini S, Savino A, Marcovecchio ML, Tumini S, Chiarelli F, Mohn A. The effect of obesity and type 1 diabetes on renal function in children and adolescents. Pediatr Diabetes. 2015;16(6):427-33. doi: 10.1111/pedi.12196. [PubMed: 25131409].

35. Hsu CY, McCulloch CE, Iribarren C, Darbinian J, Go AS. Body mass index and risk for end-stage renal disease. Ann Intern Med. 2006;144(1):21-8. [PubMed: 16389251].

36. Savino A, Pelliccia P, Giannini C, de Giorgis T, Cataldo I, Chiarelli F, et al. Implications for kidney disease in obese children and adolescents. Pediatr Nephrol. 2011;26(5):749-58. doi: 10.1007/s00467-010 1659-y. [PubMed: 21308381].

37. Sanad M, Gharib A. Evaluation of microalbuminuria in obese children and its relation to metabolic syndrome. Pediatr Nephrol. 2011;26(12):2193-9. doi: 10.1007/s00467-011-1931-9. [PubMed: 21638155].

38. Correia-Costa L, Afonso AC, Schaefer F, Guimaraes JT, Bustorff M, Guerra A, et al. Decreased renal function in overweight and obese prepubertal children. Pediatr Res. 2015;78(4):436-44. doi: 10.1038/pr.2015.130. [PubMed: 26151492].

39. Hogg RJ, Furth S, Lemley KV, Portman R, Schwartz GJ, Coresh J, et al National Kidney Foundation's Kidney Disease Outcomes Quality Initiative clinical practice guidelines for chronic kidney disease in children and adolescents: evaluation, classification, and stratification. Pediatrics. 2003;111(6 Pt 1):1416-21. [PubMed: 12777562].

40. Fan L, Inker LA, Rossert J, Froissart M, Rossing P, Mauer M, et al Glomerular filtration rate estimation using cystatin $C$ alone or combined with creatinine as a confirmatory test. Nephrol Dial Transplant. 2014;29(6):1195-203. doi: 10.1093/ndt/gft509. [PubMed: 24449101]. [PubMed Central: PMC4471437]. 